\title{
NILAI EKONOMI JASA WISATA PULAU TANGKIL PROVINSI LAMPUNG DENGAN PENDEKATAN METODE BIAYA PERJALANAN
}

\section{(ECONOMIC VALUE OF TOURISM SERVICES TANGKIL ISLAND LAMPUNG PROVINCE WITH THE TRAVEL COST METHOD APPROACH)}

\author{
Ahmad Effendi ${ }^{1}$, Samsul Bakri ${ }^{2}$, dan Rusita ${ }^{2}$ \\ ${ }^{1}$ MahasiswaJurusan Kehutanan Fakultas Pertanian Universitas Lampung \\ ${ }^{2}$ Dosen danPeneliti Jurusan Kehutanan Fakultas Pertanian Universitas Lampung \\ J1. Soemantri Brojonegoro No. 01 Bandar Lampung \\ Email : adureffendi@gmail.com \\ Phone : 081367466843
}

\begin{abstract}
ABSTRAK
Pulau Tangkil merupakan salah satu objek wisata di Provinsi Lampung yang relatif baru dikembangkan dan belum diketahui nilai ekonomi bagi banyak pengunjung, sehinggaperlu dilakukan penelitian dengan tujuan menentukan nilai ekonomi jasa wisata Pulau Tangkil dan mengetahui pengaruh karakteristik pengunjung terhadap nilai ekonomi jasa wisata. Manfaat hasil penelitian dapat digunakan sebagai bahan pertimbangan dalam menentukan kebijakan pengelolaan dan pengembangan objek wisata ini ke depan. Penelitian dilaksanakan bulan Desember 2014-Maret 2015 dengan wawancara langsung menggunakan kuisioner kepada 105 orang responden. Penentuan hasil optimasi parameter biaya perjalanan pengunjung kemudian diuji dengan metode regresi linear berganda, menggunakan software Minitab 16. Hasil penelitian mengungkapkan biaya perjalanan total pengunjung sebesar Rp37.927.000/kali kunjungan, biaya rata-rata perjalanan pengunjung sebesar Rp361.209 /orang/kali kunjungan. Nilai ekonomi jasa wisata sebesar Rp10.888.284.096/Tahun. Variabel tingkat pendidikan pada jenjang tamat SMA, jenis pekerjaan pada pengusaha, pekerjaan tambahan, pendapatan, tanggungan dalam keluarga, asal pengunjung, waktu berkunjung ketika Imlek, Natal dan Tahun Baru, serta cara berkunjung yang memiliki nilai $\mathrm{P}_{\text {value }}<0,1$ sehingga variabel independen tersebut mempunyai pengaruh bermakna terhadap nilai ekonomi jasa wisata Pulau Tangkil. Besarnya simpangan baku (S) adalah 77,20 sedangkan pengaruh variabel dependen secara simultan (R-Sq) adalah 78,6\% dan $\mathrm{R}-\mathrm{Sq}(\mathrm{adj})$ adalah 70,2\%.
\end{abstract}

Kata kunci : Pulau Tangkil, biaya perjalanan, nilai ekonomi jasa wisata

\section{ABSTRACT}

Tangkil island is one of the attractions in the province of Lampung is a relatively new development and the economic value is not known for many visitors. It is therefore necessary to research with the aim of determining the economic value of tourism services Tangkil Island and determine the effect of the characteristics of the visitors to the economic value of tourism services. Benefits of the research results can be used as a material consideration in determining management policies and the development of this attraction to the next. Research was conducted in December 2014-March 2015 with direct interview using questionnaires to 105 respondents. Determination of the results of the optimization parameters visitors travel costs were then tested by multiple linear regression method, using the software Minitab 16. The results reveal the total cost of the trip visitors $\mathrm{Rp} 37.927 .000 / v i s i t$, the average cost of the trip visitors Rp361,200/person/visit. The economic value of travel services Rp10.888.284.096/year. The variable level of education at the level graduated from high school, the type of work to employers, additional employment, income, dependents in the 
family, the origin of visitors, visiting times when the Chinese New Year, Christmas and New Year, as well as the way of a visit has a $P_{\text {value }}<0.1$ so that the independent variables these have a significant influence on the economic value of tourism services Tangkil Island. The amount of standard deviation $(S)$ is 77.20, while simultaneously influence the independent variable $(R-S q)$ is $78.6 \%$ and $R-S q$ (adj) is $70.2 \%$.

Keywords: Tangkil Island, cost of travel, economic value of tourism services

\section{PENDAHULUAN}

Pariwisata merupakan salah satu industri terbesar dalam sektor jasa dengan tingkat pertumbuhan paling pesat di dunia saat ini, bersama dengan industriteknologi dan informasi, industri pariwisata diperkirakan menjadipenggerak utama perekonomian abad 21 (Shanty, 2011). Pariwisata sebagai sebuah industri jasa, digunakan sebagai salah satu pendorong perekonomian dunia. Pariwisata semakin berkembang sejalan dengan perubahan-perubahan sosial, budaya, ekonomi, teknologi, dan politik.Semakin meratanya distribusi sumberdaya ekonomi, ditemukannya teknologi transportasi, dan peningkatan waktu luang yang didorong oleh penyusutan jam kerja telah mempercepat mobilitas manusia antar daerah, negara khususnya dalam hal pariwisata(Damanik dan Weber, 2006).

Industri pariwisata memiliki hal yang cukup penting yakni layanan pariwisata atau jasa wisata. Jasa wisata merupakan aktivitas perekonomian yang bercorak industridan memiliki nilai ekonomi dengan rente ekonomi yang relatif tinggi, dibanding dengan ekstraksi sumber daya alam lain seperti logging atau penebangan kayu, maupun penambangan gas bumi, batu bara, dan energi hasil lainya. Nilai hasil hutan kayu diperkirakan hanya sekitar lima persen dari nilai total hutan, sisanya adalah hasil hutan non kayu dan jasa lingkungan seperti wisata (Mawardi dan Sudaryono, 2006).

Pendekatan yang dapat dilakukan untuk mengetahui nilai ekonomi jasa wisata adalah dengan teknik pengukuran tidak langsung berupa travel cost method (TCM) atau metode biaya perjalanan. Penentuan nilai jasa wisata dengan metode ini sangat bergantung pada penilai (pengunjung) sehingga perlu diketahuikarakteristik pengunjung objek wisata tersebut. Hasil dari nilai ekonomi jasa wisata dapat menjadi salah satu bahan pertimbangan dalam pengembangan bentuk-bentuk layanan oleh manajemen pengelola objek wisata (Fauzi, 2013).

Objek wisata Pulau Tangkil adalah salah satu objek wisata di Provinsi Lampung yang masih mengembangkan bentuk-bentuk layanan bagi pengunjungnya. Objek wisata ini relatif baru dikembangkan dan belum diketahui nilai ekonominya bagi pengunjung, baik dari dalam maupun luar Provinsi Lampung.Masyarakat umumnya belum mengetahui objek wisata ini, akibatnya seringkali pengunjung yang datang tidak melalui dermaga penyeberangan utama sehingga menyebabkan pengunjung mengeluarkan biaya wisata lebih mahal untuk menikmati objek wisata Pulau Tangkil. Perlu dilakukan penilaian jasa wisata Pulau Tangkil dengan pendekatan metode biaya perjalanan yang berkaitan dengan karakteristik pengunjung. Hasil Penilaian ini dapat menjadi salah satu bahan pertimbangan dalam mengambil keputusan kebijakan pengelolaan dan pengembangan objek wisata Pulau Tangkil kedepan.

\section{METODE PENELITIAN}

Penelitian dilaksanakan di Obyek Wisata Pulau Tangkil yang terletak di Desa Sukajaya Lempasing, Kecamatan Padang Cermin, Kabupaten Pesawaran, Provinsi Lampung. Waktu Penelitian dilaksanakan pada Desember 2014 - Maret 2015.Bahan dari penelitian ini adalah Pengunjung Obyek Wisata Pulau Tangkil yang kemudian disebut sebagai Responden setelah bersedia menjawab kuisioner. Alat yang digunakan berupa kuisioner, alat tulis, papan, 
kamera, microsoft office dan software minitab 16.Jenis Datayang diambil dalam penelitian ini adalah data primer dan data sekunder.Data primer adalah data yang diambil secara langsung di lapangan, data ini berupa data biaya perjalanan dan karakteristik pengunjung.Data Sekunder merupakan data pustaka yang didapat dari pengelola maupun pihak lain berupa data kondisi umum dan jumlah pengunjung di Objek Wisata Pulau Tangkil dan juga literatur sebagai penunjang dalam penelitian.

Penentuan sampel penelitian yakni dengan menunjuk pengunjung yang datang baik individu maupun berkelompok dan dipilih satu atau beberapa orang sebagai wakil. Diketahui jumlah pengunjung yang datang ke Pulau Tangkil sepanjang tahun 2014 adalah sebanyak 30.144 orang (Pengelola Pulau Tangkil, 2015). Berdasarkan data tersebut jumlah populasi menunjukkan angka lebih besar dari 100 sehingga dalam penelitian ini digunakan batas error 10\% (Arikunto,2003). Penentuantersebut dilakukan guna dapat mengurangi penyimpangan dengan batas error $\leq 0,1$ alpha. Guna menentukan sampel dari populasi tersebut digunakan rumus untuk menentukan sampel pengunjung yaitu menggunakan rumus Slovin (Arikunto, 2003 dan Umar, 2007) sebagai berikut:

$$
n=\frac{N}{N(e)^{2}+1}
$$

$$
\begin{aligned}
& n=\frac{30.144}{30.144(10 \%)^{2}+1} \\
& n=99,669356 \\
& n \approx 100 \\
& \text { Keterangan: } \\
& n \quad=\text { Jumlah sampel } \\
& \mathrm{N} \quad=\text { Jumlah pengunjung } \\
& e \quad=\text { Nilai kritis (batas penelitian) yang diinginkan (persen kelonggaran } \\
& 1 \quad=\quad \text { ketidaktelitian karena kesalahan pengambilan sampel) } \\
& \text { Bilangan konstan }
\end{aligned}
$$

Berdasarkan perhitungan tersebut didapat jumlah sampel yang harus diambil minimal sebanyak 100 orang responden.

\section{Nilai Ekonomi Wisata Pulau Tangkil}

Perhitungan besarnya biaya perjalanan pengunjung untuk berwisata ke Pulau Tangkil menggunakan rumus seperti yang digunakan oleh Sulistiyono (2007) sebagai berikut :

$$
\mathrm{BPT}=\mathrm{BTr}+\mathrm{BD}+(\mathrm{BKr}-\mathrm{BKh})+\mathrm{L}) .
$$

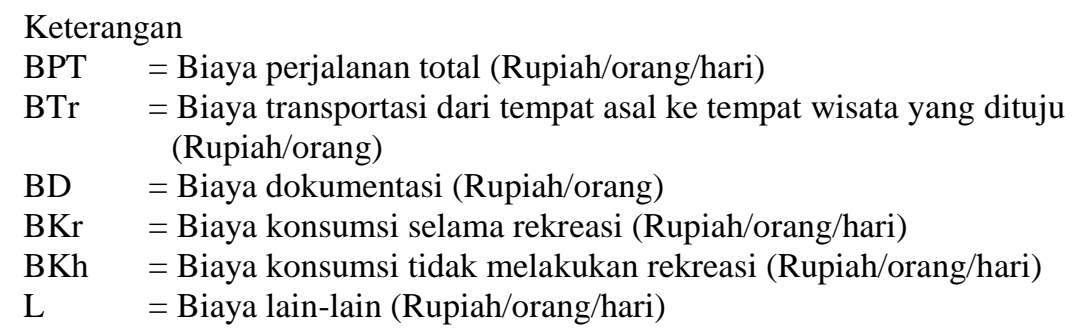

Dan untuk perhitungan besarnya biaya rata-rata perjalanan pengunjung untuk menuju wisata Pulau Tangkil menggunakan rumus seperti dibawah ini (Ekwarso, 2010), 


$$
A T C=\sum \frac{B P T}{n}
$$

Keterangan

ATC = Biaya rata-rata perjalanan pengunjung

$\mathrm{n} \quad=$ Jumlah pengunjung yang diwawancarai

$\mathrm{BPT}=$ Jumlah total biaya perjalanan pengunjung

Total biaya perjalanan pengunjung wisata Pulau Tangkil dapat dihitung dengan menggunakan rumus seperti dibawah ini (Ekwarso, 2010),

$$
T T C=\sum_{i=1}^{105} A T C \frac{n i}{N}
$$

Keterangan

TTC = Total biaya perjalanan

$\mathrm{N} \quad=$ Jumlah total pengunjung

ATC = Rata-rata biaya perjalanan

$\mathrm{ni} \quad=$ Jumlah pengunjung yang diwawancarai

Biaya rata-rata perjalanan per zona dihitung berdasarkan rumus yang digunakan oleh Purwanto(2013) sebagai berikut:

$$
\mathrm{ATCi}=\frac{\Sigma_{\mathrm{i}=1 \mathrm{BPT} \mathrm{ji}}^{99}}{\mathrm{Ni}}
$$

Keterangan :

$\mathrm{ATCi}=$ Biaya perjalanan rata-rata dari zona i (rupiah/hari orang kunjungan)

$\mathrm{BPTji}=$ Jumlah total biaya perjalanan ke $\mathrm{j}$ dari zona I (rupiah/hari orang

$\mathrm{Ni} \quad \begin{aligned} & \text { kunjungan) } \\ & \text { = Jumlah total pengunjung dari zona i (orang) }\end{aligned}$

Nilai ekonomi obyek wisata kemudian dapat diketahui dari biaya perjalanan rata - rata pengunjung yang kemudian dikalikan dengan jumlah total pengunjung selama satu tahun (Sulistiyono, 2007 dalam Siregar, 2010).

\section{Analisis dan pemodelan Karakteristik Pengunjung}

Pemodelan dan uji hipotesi dalam penelitian ini menggunakan pendekatan model regresi linear berganda. Secara matematik seperti yang disajikan pada persamaan berikut ini :

$$
\begin{aligned}
& \mathrm{Y}_{\mathrm{i}}=\alpha_{0}+\alpha_{1}\left[\mathrm{X}_{1}\right]_{\mathrm{i}}+\alpha_{2}\left[\mathrm{X}_{2}\right]_{\mathrm{i}}+\alpha_{3}\left[\mathrm{X}_{3}\right]_{\mathrm{i}}+\alpha_{4}\left[\mathrm{X}_{4}\right]_{\mathrm{i}}+\alpha_{5}\left[\mathrm{X}_{5}\right]_{\mathrm{i}}+\alpha_{6}\left[\mathrm{X}_{6}\right]_{\mathrm{i}}+\alpha_{7}\left[\mathrm{X}_{7}\right]_{\mathrm{i}}+\alpha_{8}\left[\mathrm{X}_{8}\right]_{\mathrm{i}} \\
& +\alpha_{9}\left[\mathrm{X}_{9}\right]_{\mathrm{i}}+\alpha_{10}\left[\mathrm{X}_{10}\right]_{\mathrm{i}}+\alpha_{11}\left[\mathrm{X}_{11}\right]_{\mathrm{i}}+\alpha_{12}\left[\mathrm{X}_{12}\right]_{\mathrm{i}}+\alpha_{13}\left[\mathrm{X}_{13}\right]_{\mathrm{i}}+\alpha_{13}\left[\mathrm{X}_{14}\right]_{\mathrm{i}}+\alpha_{15}\left[\mathrm{X}_{15}\right]_{\mathrm{i}} \\
& +\alpha_{16}\left[\mathrm{X}_{16}\right]_{\mathrm{i}}+\text { ei... }
\end{aligned}
$$

\begin{tabular}{llll}
\multicolumn{2}{l}{ Keterangan } & & \\
$\mathrm{Y}$ & $=$ Biaya perjalanan pengunjung wisata Pulau Tangkil & \\
{$\left[\mathrm{X}_{1}\right]_{\mathrm{i}}$} & $=$ Kelamin & {$\left[\mathrm{X}_{10}\right]_{\mathrm{i}}$} & $=$ Motivasi \\
{$\left[\mathrm{X}_{2}\right]_{\mathrm{i}}$} & $=$ Umur & {$\left[\mathrm{X}_{11}\right]_{\mathrm{i}}$} & $=$ Waktu Berkunjung \\
{$\left[\mathrm{X}_{3}\right]_{\mathrm{i}}$} & $=$ Pendidikan & {$\left[\mathrm{X}_{12}\right]_{\mathrm{i}}$} & $=$ Cara Berkunjung \\
{$\left[\mathrm{X}_{4}\right]_{\mathrm{i}}$} & $=$ Pekerjaan & {$\left[\mathrm{X}_{13}\right]_{\mathrm{i}}$} & $=$ Kendaraan \\
{$\left[\mathrm{X}_{5}\right]_{\mathrm{i}}$} & $=$ Pekerjaan Tambahan & {$\left[\mathrm{X}_{14}\right]_{\mathrm{i}}$} & $=$ Waktu Luang \\
{$\left[\mathrm{X}_{6}\right]_{\mathrm{i}}$} & $=$ Pendapatan & {$\left[\mathrm{X}_{15}\right]_{\mathrm{i}}$} & $=$ Frekuensi Berkunjung \\
{$\left[\mathrm{X}_{7}\right]_{\mathrm{i}}$} & $=$ Pernikahan & {$\left[\mathrm{X}_{16}\right]_{\mathrm{i}}$} & $=$ Pintu Masuk \\
{$\left[\mathrm{X}_{8}\right]_{\mathrm{i}}$} & $=$ Tanggungan & $\alpha$ & $=$ Konstanta \\
{$\left[\mathrm{X}_{9}\right]_{\mathrm{i}}$} & $=$ Asal Pengunjung & $\mathrm{ei}$ & $=$ Standar error
\end{tabular}




\section{HASIL DAN PEMBAHASAN}

\section{Nilai Ekonomi Jasa Wisata Pulau Tangkil}

\section{Biaya Perjalanan Total}

Nilai penyediaan suatu barang dan jasa dapat didekati dari didekati kesediaan membayar para konsumen (Darusman,1993 dalam Djijono, 2002). Nilai ekonomi jasa wisata Pulau Tangkil dapat diketahui melalui biaya perjalanan yang dikeluarkan pengunjung untuk mencapai objek wisata tersebut (Tambunan, 2013). Berdasarkan penelitian yang telah dilakukan pada objek wisata Pulau Tangkil memperoleh data biaya perjalanan total yang dikeluarkan pengunjung adalah sebesar Rp37.927.000/kali kunjungan, dengan demikian nilai ekonomi jasa wisata Pulau Tangkil dapat diketahui melalui biaya perjalanan yang dikeluarkan oleh pengunjung untuk mencapai objek wisata tersebut,

\section{Biaya Perjalanan Rata-Rata}

Penentuan nilai ekonomi jasa wisata dilakukan, setelah terlebih dahulu mengetahui biaya perjalanan rata-rata pengunjung suatu objek wisata (Safitridkk, 1996). Untuk mengetahuinya maka biaya perjalanan total pengunjung objek wisata Pulau Tangkil diketahui sebesar Rp37.927.000 dibagi dengan jumlah responden yang telah mengisi kuisioner sebanyak 105 orang. Dengan demikian biaya perjalanan rata - rata yang dikeluarkan oleh pengunjung objek wisata Pulau Tangkil yang diperoleh adalah sebesar Rp361.209/orang/kali kunjungan dan salah satu indikator yang mempengaruhi besarnya biaya perjalanan adalah letak suatu objek wisata dari rumah atau tempat tinggal pengujung.

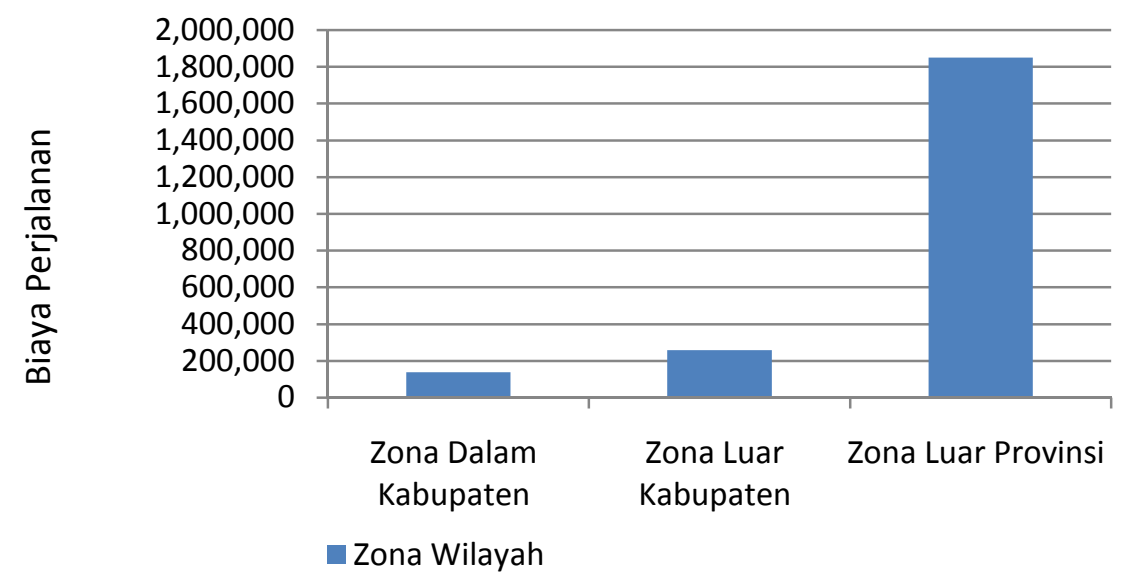

Sumber : Olahan data primer (2015)

Gambar 1. Biaya perjalanan rata - rata per zona

Biaya perjalanan rata - rata berdasarkan zona asal pengunjung diketahui dari zona dalam kabupaten sebesar Rp138.571/zona/kali kujungan, dari zona luar kabupaten atau zona dalam provinsi sebesar Rp259.198/zona/kali kunjungan, dan zona luar provinsi sebesar Rp1.850.000/zona/kali kunjungan. Berdasarkan data penelitian tersebut diketahui biaya perjalanan terbesar diperoleh dari zona luar provinsi dengan nilai Rp1.850.000 /zona/kali kunjungan. 


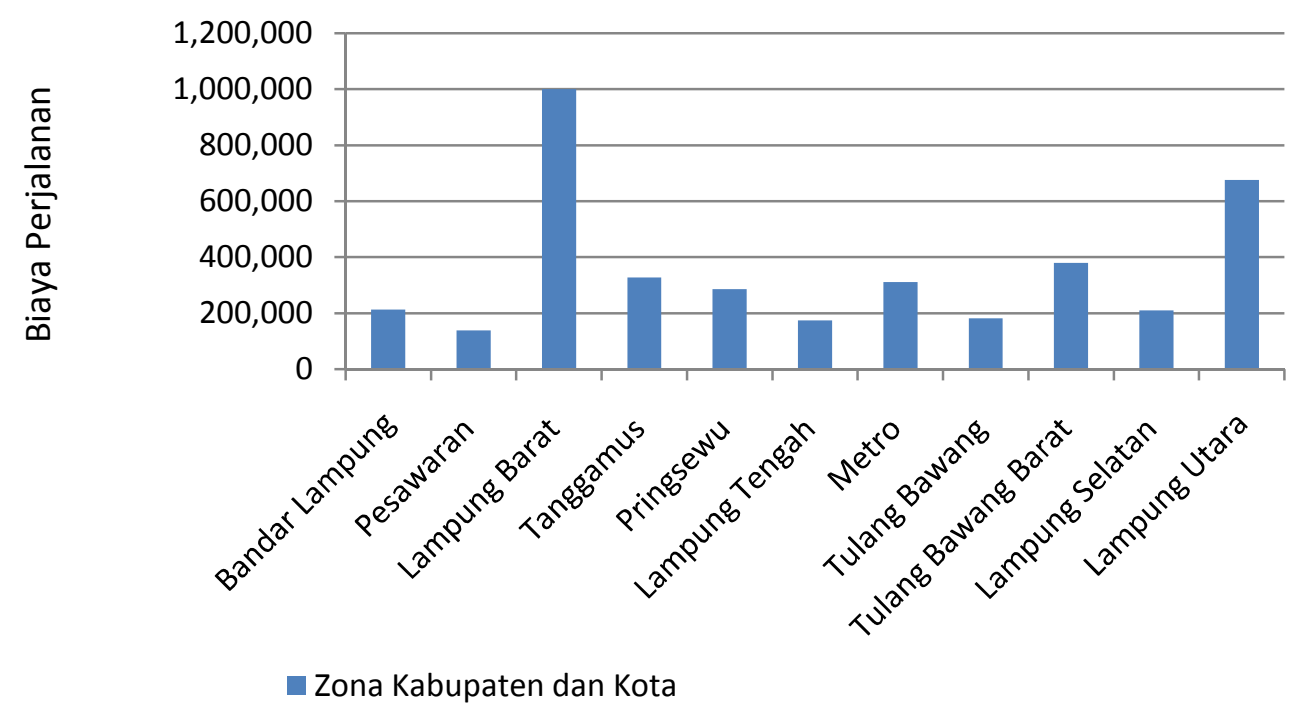

Sumber : Olahan data primer (2015)

Gambar 2. Biaya perjalanan rata - rata per daerah

Biaya perjalanan berdasarkan daerah asal pengunjung diketahui terkecil berasal dari Kabupaten Pesawaran sebesar Rp138.571/zona/kali kunjungan, sedangkan terbesar dari Kabupaten Lampung Barat sebesar Rp1.000.000/zona/kali kunjungan.Biayatersebut dikarenakan semakin jauh daerah asal pengunjung mengakibatkan pengeluaran akan biaya perjalanan semakin tinggi (Sihotang, 2014).

\section{Nilai Ekonomi Jasa Wisata}

Nilai ekonomi jasa wisata dapat diketahui dengan cara mengkalikan biaya perjalanan rata-rata pengunjung dengan jumlah pengunjung selama tahun (Sulistiyono, 2007). Perhitungan data penelitian memperoleh nilai ekonomi jasa wisata Pulau tangkil sebesar Rp10.888.284.096/tahun. Nilai tersebut diperoleh dari biaya rata-rata perjalanan pengunjung sebesar Rp361.209/orang/kunjungan dikalikan dengan jumlah pengunjung selama 2014 sebanyak 30.144 orang. Nilai ekonomi tersebut menunjukkan bahwa objek wisata Pulau Tangkil memiliki nilai ekonomi relatif tinggi, jika dibandingkan dengan wisata pantai lain seperti wisata pantai Hunimua yang berada di kota Ambon, hanya memiliki nilai ekonomi sebesar Rp1.174.944.301/tahun (Wawo dkk., 2008). Nilai ekonomi ini tentunya dapat ditingkatkan mengingat di objek wisata lain seperti taman wisata alam laut Pulau Weh memiliki nilai ekonomi mencapai Rp30.902.587.657/tahun (Sobari dkk., 2006). Peningkatan tersebut dapat melalui pengembangan objek wisata guna menambah daya tarik Pulau Tangkil sebagai objek wisata seperti penambahan fasilitas, kerjasama dengan stakeholders, melakukan promosi serta mengadakan event-event sosial budaya sebagai atraksi pada saat momenmomen ketika pengunjung banyak hadir, sehingga pengunjung puas akan pelayanan jasa wisata dan kembali berkunjung dilain waktu (Wawo dkk., 2008).

\section{Karakteristik Pengunjung}

Berdasarkanpenelitian yang telahdilakukan, diketahuikarakteristik pengunjung objek wisata Pulau Tangkil, kemudian dipersentasikan seperti pada tabel1. berikut : 
Tabel1. Karakteristik Pengunjung, Jumlah, Persentase dan Simpangan Baku

\begin{tabular}{|c|c|c|c|c|c|}
\hline \multirow{2}{*}{$\begin{array}{l}\text { No } \\
1\end{array}$} & \multicolumn{2}{|c|}{ Karakteristik Pengunjung } & \multirow{2}{*}{$\begin{array}{r}\text { Jumlah } \\
63\end{array}$} & \multirow{2}{*}{$\begin{array}{r}\text { Persentase (\%) } \\
60,00\end{array}$} & Simpangan Baku \\
\hline & JenisKelamin & Laki - Laki & & & - \\
\hline & & Perempuan & 42 & 40,00 & \\
\hline \multirow[t]{6}{*}{2} & KelompokUmur & $\leq 20$ & 5 & 4,76 & 9,858449 \\
\hline & & $20-30$ & 49 & 46,67 & \\
\hline & & $30-40$ & 17 & 16,19 & \\
\hline & & $40-50$ & 10 & 9,50 & \\
\hline & & $50-60$ & 4 & 3,81 & \\
\hline & & $60 \leq$ & 0 & 0,00 & \\
\hline \multirow[t]{4}{*}{3} & Tingkat pendidikan & $\leq \mathrm{SD}$ & 3 & 2,86 & - \\
\hline & & SMP & 2 & 1,91 & \\
\hline & & SMA & 22 & 20,95 & \\
\hline & & $\mathrm{PT} \leq$ & 78 & 74,28 & \\
\hline \multirow[t]{6}{*}{4} & JenisPekerjaan & Petani & 3 & 2,86 & - \\
\hline & & Mahasiswa & 20 & 19,05 & \\
\hline & & IRT/Tidak bekerja & 16 & 15,24 & \\
\hline & & Swasta & 27 & 25,71 & \\
\hline & & PNS & 21 & 20,00 & \\
\hline & & Pengusaha & 18 & 17,14 & \\
\hline \multirow[t]{2}{*}{5} & PekerjaanTambahan & Ada & 18 & 17,14 & - \\
\hline & & Tidak ada & 87 & 82,86 & \\
\hline \multirow[t]{5}{*}{6} & Pendapatan (Juta) & $\leq 2$ & 39 & 37,14 & 2612,01086 \\
\hline & & $2-3$ & 35 & 33,34 & \\
\hline & & $3-4$ & 5 & 4,76 & \\
\hline & & $4-5$ & 13 & 12,38 & \\
\hline & & $5 \leq$ & 13 & 12,38 & \\
\hline \multirow[t]{2}{*}{7} & Status Pernikahan & Menikah & 68 & 64,76 & - \\
\hline & & BelumMenikah & 37 & 35,24 & \\
\hline \multirow[t]{6}{*}{8} & JumlahTanggungan & 0 & 38 & 36,19 & 1,427234 \\
\hline & & 1 & 13 & 12,38 & \\
\hline & & 2 & 28 & 26,67 & \\
\hline & & 3 & 12 & 11,43 & \\
\hline & & 4 & 12 & 11,43 & \\
\hline & & $5 \leq$ & 2 & 1,90 & \\
\hline \multirow[t]{12}{*}{9} & AsalPengunjung & Pesawaran & 7 & 6,67 & - \\
\hline & & Bandar Lampung & 51 & 48,57 & \\
\hline & & Lampung Barat & 1 & 0,95 & \\
\hline & & Tanggamus & 11 & 10,48 & \\
\hline & & Pringsewu & 5 & 4,76 & \\
\hline & & Lampung Tengah & 7 & 6,67 & \\
\hline & & Metro & 5 & 4,76 & \\
\hline & & Tulang Bawang & 2 & 1,90 & \\
\hline & & Tulang Bawang Barat & 2 & 1,90 & \\
\hline & & Lampung Selatan & 4 & 3,81 & \\
\hline & & Lampung Utara & 3 & 2,86 & \\
\hline & & Luar Provinsi & 7 & 6,67 & \\
\hline 10 & MotivasiPengunjung & Tujuan Utama & 99 & 94,28 & - \\
\hline & & Bersinggah & 6 & 5,72 & \\
\hline 11 & WaktuBerkunjung & Hari Biasa & 15 & 14,28 & - \\
\hline & & Akhir Pekan & 15 & 14,28 & \\
\hline & & Nyepi & 15 & 14,28 & \\
\hline & & Imlek & 15 & 14,28 & \\
\hline & & Natal & 20 & 19,06 & \\
\hline & & Tahun Baru & 25 & 23,82 & \\
\hline 12 & JenisKendaraan & Pribadi & 102 & 97,14 & - \\
\hline & & Sewa/lainya & 3 & 2,86 & \\
\hline 13 & Cara Berkunjung & 1 & 1 & 0,95 & 1,714354 \\
\hline & & $(2-5)$ & 87 & 82,85 & \\
\hline & & $(6-11)$ & 17 & 16,19 & \\
\hline 14 & WaktuLuang & Ada & 80 & 76,19 & - \\
\hline & & Tidak Ada & 25 & 23,81 & \\
\hline 15 & JumlahBerkunjung/Tahun & $\leq 1$ & 57 & 54,29 & 0,717648 \\
\hline & & 2 & 48 & 45,71 & \\
\hline 16 & PintuKunjungan & DermagaSukajaya & 75 & 71,43 & - \\
\hline & & PantaiMutun MS T & 29 & 27,62 & \\
\hline & & Pintu Lainya & 1 & 0,95 & \\
\hline
\end{tabular}

Sumber : Olahan Data Primer (2015) 
Karakteristik responden merupakan bagian terpenting dari suatu penelitiankarena dengan mengetahui karakteristik responden kita dapat mengenal objek penelitian kita dengan lebih baik (Mateka dkk, 2015). Berdasarkan penelitian yang telah dilakukan, diketahui beragam karakteristk pengunjung objek wisata Pulau Tangkil. Karakteristik tersebut diantaranya jenis kelamin dari data responden mayoritas adalah laki-laki sebanyak 63 orang atau setara $60 \%$, sedangkan jenis kelamin perempuan sebanyak 42 orang atau setara $40 \%$. Pengunjung yang datang ke objek wisata Pulau Tangkil berdasarkan umur diketahui mayoritas pengunjungnya berumur 20 sampai 30 tahun, dengan jumlah sampel data responden pengunjung sebanyak 49 orang atau persentase sebesar $46,67 \%$. Pengunjung dengan tingkatan pendidikan Perguruan Tinggi sebanyak 78 orang atau setara dengan $74,28 \%$, dan untuk tingkatan pendidikan SMA sebanyak 22 orang atau setara dengan 20, 95 $\%$ sedangkan untuk tingkatan SMP dan SD hanya menunjukkan angka dibawah 5\%. Pengunjung objek wisata Pulau Tangkil diketahui pegawai swasta menunjukkan angka tertinggi dengan persentase sebesar $25,71 \%$. Jenis pekerjaan menunjukan angka paling sedikit adalah Petani dengan persentase $2,86 \%$.

Penelitian ini diketahui pengunjung yang memiliki pekerjaan tambahan hanya $16,24 \%$. Sisanya hanya mengandalkan pekerjaan pokok sebagai tumpuan hidup. Tingkatan pendapatan dari pengunjung objek wisata Pulau Tangkil paling banyak ditunjukkan pada angka $\leq 2 \mathrm{jt}$ rupiah dengan persentase $37,14 \%$. Tingkatan pendapatan paling sedikit diperoleh pada kisaran $3 \mathrm{jt}-4 \mathrm{jt}$ rupiah dengan persentase $4,76 \%$. Penelitian menunjukkan pengunjung yang telah menikah memiliki angka persentase terbesar yakni 64,76\% dibandingkan dengan yang belum menikah sebesar 35,24\%. Pengujung dengan tanpa ada tanggungan menunjukkan angka tertinggi dengan persentase $36,19 \%$, sedangkan dengan jumlah tanggungan $5 \leq$ menunjukkan angka terendah dengan persentase $1,90 \%$. Penelitian ini menunjukkan pengunjung asal Kota Bandar Lampung memiliki persentase tertinggi dalam hal jumlah pengunjung sebesar 48,57\%. Berbeda dengan pengunjung asal Lampung Barat yang hanya menunjukkan angka $0,95 \%$. Berdasarkan penelitian ini diketahui motivasi utama pengunjung objek wisata Pulau Tangkil untuk berekreasi atau piknik sebesar 94,28\%. Penelitian ini menunjukkan Pengunjung yang datang pada momen akhir tahun yakni Natal dan Tahun Baru diketahui sebesar $42,88 \%$. Penelitian ini diketahui hampir seluruh pengunjung objek wisata Pulau Tangkil menggunakan kendaraan pribadi guna mecapai wisata ini, hal ini terlihat dari angka yang menunjukkan persentase sebesar $97,14 \%$ pengunjung yang menggunakan kendaraan pribadi.

Berdasarkan penelitian ini diketahui pengunjung yang memiliki waktu luang 2 hari menunjukkan persentase terbesar yakni sebanyak 54,29\%. Berdasarkan penelitian diketahui Persentase tertinggi didapat pada kelompok 2-3 orang perkali kunjungan sebesar $82,85 \%$. Pantai ataupun dermaga yang sering dilalui pengunjung adalah Dermaga Sukajaya yang berada tidak jauh dengan pintu Pantai Mutun. Penelitian ini mengungkapkan angka persetase data yang menunjukkan sebasar $71,43 \%$ pengunjung melalui jalan ataupun dermaga tersebut.

Berdasarkan data yang diperoleh, dilakukan analisis regresi untuk mengetahui variabel variabel karakteristik yang memiliki pengaruh terhadap biaya perjalanan sebagai penentu nilai ekonomi suatu jasa wisata. Penelitian kali ini mengkorelasikan biaya perjalanan menuju objek wisata Pulau Tangkil dengan karakteristik pengunjungnya menggunakan software Minitab 16. Persamaan regresi linear berganda, biaya perjalanan dianggap sebagai variabel dependen atau variabel terikat (variabel Y), sedangkan variabel-variabel lainya dianggap sebagai variabel independen (variabel $\mathrm{X}$ ). Pengujian regresi linear berganda dapat menggunakan persamaan sebagai berikut : 
$\mathrm{Yi}_{\mathrm{i}}=242$ - 20,0 KLi + 5,71 UMi + 132 D1_SMPi + 108 D1_SMAi + 63,1 D1_PTi

+ 40,8 D2_MHSi + 17,5 D2_IRTi + 48,3 D2_SWTA $i+50,9$ D2_PNS $i$

+ 109 D2_USHi + 42,9 PKJ TBi + 0,0232 PDTi + 12,8 ST MNi $+47,5 \mathrm{TGG}_{\mathrm{i}}$

+ 31,4 D3_L KABi + 415 D3_L PROVi - 65,6 MTVi + 73,4 D4_WNi

+ 40,5 D4_NYEPI + 101 D4_IMLEKi + 71,7 D4_NATLi + 124 D4_N YRi

+ 31,5 CR BKJi - 20,4 KNDi + 92,0 WLi + 12,0 FR BKJi +26,9 PNT MTNi

Berdasarkan persamaan tersebut maka dapat diperoleh hasil perhitungan regresi linear berganda melalui software minitab, yang mengukapkan pengaruh variabel-variabel $\mathrm{X}$ terhadap variabel $\mathrm{Y}$, dengan penjabaran analisis data sebagai berikut:

\section{Uji F Regresi}

Guna menentukan apakah secara simultan semua variabel independen mempunyai pengaruh yang bermakna terhadap variabel dependen, dapat dilihat dari nilai uji $\mathrm{F}$ sebagai berikut :

Tabel 2. Analysis of Variance

\begin{tabular}{lrrrrr}
\hline Source & DF & SS & MS & F & P \\
& & & & & \\
\hline Regression & 27 & 1509705 & 55915 & 9,38 & 0,000 \\
$\begin{array}{l}\text { Residual Error } \\
\text { Total }\end{array}$ & 96 & 411259 & 5960 & & \\
\hline \multicolumn{5}{l}{ Durbin-Watson statistic $=\mathbf{1 , 8 4 4 7 0}$} \\
\hline
\end{tabular}

Sumber : Olahan Data Primer(2015)

Berdasarkan data tabel 5.3 diketahui nilai P Regression pada Analysis of Variance sebesar 0,000 di mana < 0,1 maka disimpulkan bahwa secara simultan variabel independen mempunyai pengaruh bermakna terhadap variabel dependen.

\section{Uji T Regresi Linear}

Guna mengetahui bahwa 16 variabel independen (X) yang telah di spesifikasikan menjelaskan pengaruhnya terhadap variabel dependen (Y) maka dapat digunakan uji $\mathrm{T}$ parsial. Berdasarkan data yang muncul diatas diketahui semua variabel independen dengan $\mathrm{p}$ value $\mathrm{t}$ parsial $<0,1$ memberikan pengaruh secara individu terhadap Y dengan memperhatikan variabel lain, seperti pada Tabel 2.terpaparkan hasil optimasi dari regresi linear berganda dengan variabel yang telah ditentukan. 
Tabel 2. Hasil Optimasi Parameter Model Nilai Ekonomi Jasa Wisata Pulau Tangkil sebagai Fungsi dari Y

\begin{tabular}{|c|c|c|c|c|c|c|c|c|}
\hline \multirow{2}{*}{$\begin{array}{l}\text { Predictor } \\
\text { Constant } \\
\end{array}$} & \multirow{2}{*}{$\begin{array}{l}\text { Keterangan } \\
\text { Ket. } \\
\end{array}$} & \multicolumn{7}{|c|}{ Coef SECoef T P } \\
\hline & & & & & 241,7 & 128,8 & 1,88 & 0,065 \\
\hline KL & Kelamin & & & & $-20,04$ & 19,76 & $-1,01$ & 0,314 \\
\hline UM & Umur & 5,706 & 2,869 & 1,99 & 0,051 & & & \\
\hline \multicolumn{9}{|l|}{ Pendidikan } \\
\hline D1_SMP & SMP & & & & 132,07 & 83,90 & 1,57 & 0,120 \\
\hline D1_SMA & SMA & & & & 107,52 & 58,72 & 1,83 & 0,071 \\
\hline D1_PT & PT & & & & 63,06 & 50,96 & 1,24 & 0,220 \\
\hline \multicolumn{9}{|l|}{ Pekerjaan } \\
\hline D2_MHS & Mahasiswa & & & & 40,77 & 67,91 & 0,60 & 0,550 \\
\hline D2_IRT & Ibu Rumah T. & & & & 17,48 & 65,55 & 0,27 & 0,791 \\
\hline D2_SWTA & Swasta & & & & 48,27 & 60,34 & 0,80 & 0,427 \\
\hline D2_PNS & Pns & & & & 50,88 & 68,49 & 0,74 & 0,460 \\
\hline D2_USH & Pengusaha & & & & 108,88 & 54,78 & 1,99 & 0,051 \\
\hline PKJ TB & P.Tambahan & & & & 42,94 & 43,41 & 0,99 & 0,026 \\
\hline PDT & Pendapatan & & & & 0,0232330 & 09012 & 2,58 & 0,012 \\
\hline ST MN & Pernikahan & & & & 12,83 & 38,20 & 0,34 & 0,738 \\
\hline TGG & Tanggungan & & & & 47,47 & 21,84 & 2,17 & 0,033 \\
\hline \multicolumn{9}{|c|}{ Asal Pengunjung } \\
\hline D3_L KAB & LuarKabupaten & & & & 31,40 & 55,48 & 0,57 & 0,573 \\
\hline D3_L PROV & Luar Provinsi & & & & 415,30 & 105,4 & 3,94 & 0,000 \\
\hline MTV & Motivasi & 65,59 & 71,79 & 0,91 & 0,364 & & & \\
\hline \multicolumn{9}{|c|}{ Waktu Berkunjung } \\
\hline D4_WN & AkhirPekan & & & & 73,37 & 36,48 & 2,01 & 0,048 \\
\hline D4_NYEPI & Nyepi & & & & 40,49 & 31,22 & 1,30 & 0,199 \\
\hline D4_IMLEK & Imlek & & & & 101,06 & 34,16 & 2,96 & 0,004 \\
\hline D4_NATL & Natal & & & & 71,74 & 31,80 & 2,26 & 0,027 \\
\hline D4_N YR & TahunBaru & & & & 123,60 & 33,19 & 3,72 & 0,000 \\
\hline KND & Kendaraan & & & & 31,511 & 6,704 & 4,70 & 0,000 \\
\hline CR BKJ & Cara Berkujung & & & & $-20,44$ & 64,93 & $-0,31$ & 0,754 \\
\hline WL & WaktuLuang & & & & 92,00 & 39,63 & 2,32 & 0,023 \\
\hline FR BKJ & FrekuensiBerkunjung & & & & 11,97 & 14,12 & 0,85 & 0,400 \\
\hline PNT MTN & PintuMutun & & & & 26,92 & 27,41 & 0,98 & 0,329 \\
\hline
\end{tabular}

$\mathrm{S}=\mathbf{7 7 , 2 0 2 8} \quad \mathrm{R}-\mathrm{Sq}=\mathbf{7 8 , 6} \% \quad \mathrm{R}-\mathrm{Sq}(\operatorname{adj})=\mathbf{7 0 , 2} \%$

Sumber : Olahan Data Primer (2015)

Pengunjung dengan karakteristik umur menunjukkan pengaruh positif secara nyata terhadap biaya perjalanan, ini terlihat dari $\mathrm{P}_{\text {value }}$ Tparsial $0,051<0,1$. Pengaruh tersebut menunjukkan ketika setiap kenaikan umur 1 tahun maka akan bertambah biaya perjalanan sebesar Rp5.710. Selaras dengan penelitian Sihotang (2014) yang menunjukkan kelompok umur memiliki pengaruh nyata dengan $\mathrm{P}_{\text {value }}$ Tparsial 0,042 dan nilai koefisien sebesar Rp6.090. 
Pengunjung dengan kategori pendidikan lulusan SMA memberikan nilai jasa wisata secara nyata lebih tinggi dari pada kategori pendidika lulusan SMP atau di bawahnya yaitu sebesar Rp107.520 seperti ditunjukan pada coef. $\beta_{4}=107,52$ dan $\mathrm{P}_{\text {value }}=0,071$. Selaras dengan penelitian Siregar (2011) tingkat kunjungan di objek wisata alam Air Terjun Sipiso-Piso Kabupaten Karo, sebagian besar tingkat pendidikan tidak memberikan pengaruh signifikan.

Pengunjung dengan kategori pekerjaan usaha (pengusaha) memberikan nilai jasa wisata secara nyata lebih tinggi dari pada kategori pekerjaan pns dan lainya yaitu sebesar Rp108.880, seperti ditunjukan pada coef. $\beta_{7}=108,88$ dan $\mathrm{P}_{\text {value }}=0,051$. Senada dengan yang diungkapkan Sihotang (2014) bahwa pekerja swasta cenderung membutuh rekreasi tinggi akibat kejenuhan tutinitas sehari-hari.

Pengunjung dengan memiliki pekerjaan tambahan memberikan pengaruh secara nyata terhadap nilai jasa wisata sebesar Rp42.940 , seperti ditunjukan pada coef. $\beta_{8}=42,94$ dan $\mathrm{P}_{\text {value }}=0,026$. Temuan ini memberi makna bahwa pengunjung dengan memiliki pekerjaan tambahan memiliki prospek yang lebih baik dari variabel jenis pekerjaan lain. Pengunjung dengan memiliki pekerjaan tambahan akan memiliki kesempatan lebih luas untuk mendapatkan kepuasan dikarenakan penghasilan seseorang berperan dalam pengambilan keputusan dalam memilih wisata (Sihotang dkk, 2014).

Pengunjung dengan tingkat pendapatan berbeda memiliki pengaruh nyata terhadap nilai jasa wisata yaitu sebesar Rp23,2333, ditunjukkan coef. $\beta_{9}=0,0232333$ dan $\mathrm{P}_{\text {value }}=0,012$. Pengunjung memiliki tanggungan memberikan nilai ekonomi jasa wisata secara nyata lebih tinggi dari pengunjung tanpa ada tanggungan sebesar Rp47.470 ribu, ditunjukkan coef. $\beta_{11}=$ 47,47 dan $\mathrm{P}_{\text {value }}=0,033$. Besarnya pendapatan menunjang seseorang melakukan kegiatan rekreasi sehingga kelompok pengunjung yang memiliki pendapatan tinggi berkesempatan rekreasi yang besar (Sihotang, 2014).

Pengunjung berasal dari luar provinsi secara nyata memberikan nilai ekonomi jasa wisata lebih besar dibanding pengunjung berasal dari luar kabupaten sebesar Rp.415.300 , ditunjukkan coef. $\beta_{12}=415,3$ dan Pvalue $=0,000$. Semakin dekat jarak yang ditempuh pengunjung menuju lokasi wisata, maka semakin kecil biaya perjalanan yang dikeluarkan (Sihotang dkk, 2014).

Pengunjung dengan motivasi kunjungan bukan utama(bersinggah) memberikan nilai jasa wisata secara tidak nyata lebih tinggi dari pengunjung dengan motivasi utama yaitu sebesar Rp65.590 seperti ditunjukan pada coef. $\beta_{14}=65,59$ dan Pvalue $=0,364$. Senada dengan yang diungkapkan Jayapalan (2001) bahwa sesorang termotivasi melakukan perjalanan antara lain faktor fisik seperti melakukan perjalanan wisata karena adanya kebutuhan dari wisatawan relaksasi dari rutinitas kerja.

Pengunjung dengan waktu kunjungan akhir pekan memberikan nilai jasa wisata secara nyata lebih tinggi dari pengunjung pada hari biasa yaitu sebesar Rp73.370 seperti ditunjukan pada coef. $\beta_{15}=73,37$ sedangkan $\mathrm{P}_{\text {value }}=0,048$. Waktu kunjungan bertepatan dengan imlek, natal dan tahun baru, pengunjung memberikan nilai ekonomi wisata secara nyata dan lebih tinggi dibanding hari nyepi dan akhir pekan, tentu akan mempengaruhi penilaian pengunjung terhadap objek wisata Pulau Tangkil. nilai merupakan persepsi seseorang mengenaiharga yang diberikan seseorang terhadap sesuatu pada suatu tempat dan waktu tertentu ( Davis dan Johson, 1987 dalam Djijono 2002).

Pengunjung yang memiliki waktu luang memberikan nilai jasa wisata secara nyata lebih tinggi dari pengunjung dengan sedikit waktu luang yaitu sebesar Rp92.000 seperti ditunjukan pada coef. $\beta_{19}=92,00$ dan Pvalue $=0,023$. Waktu luang berpengaruh terhadap keputusan pengunjung untuk memilih tempat wisata berdasarkan waktu luang yang dimiliki (Sihotang dkk, 2014). 


\section{KESIMPULAN}

Berdasarkan penelitian yang dilakukan pada objek wisata Pulau Tangkil diketahui bahwa nilai ekonomi jasa wisata Pulau Tangkil Provinsi Lampung menunjukkan angka sebesar Rp10.888.284.096/tahun, dengan biaya perjalanan rata-rata pengunjung sebesar Rp361.209/orang/kali kunjungan. Besarnya biaya perjalanan ini dipengaruhi oleh biaya yang dikeluarkan pengunjung dari rumah hingga menuju objek wisata Pulau Tangkil untuk menikmati atraksi yang ada dan juga karakteristik pengunjung yang memberikan pengaruh nyata terhadap nilai ekonomi jasa wisata Pulau Tangkil yaitu berupa pengunjung dengan memiliki tingkat pendidikan terakhir SMA, berjenis pekerjaan pengusaha, memiliki pekerjaan tambahan, berpendapatan, memiliki tanggungan dalam keluarga, asal pengunjung, waktu berkunjung ketika imlek, natal dan tahun baru, serta cara berkunjung berkelompok yang memiliki nilai $\mathrm{P}$ Value $<0,1$ sehingga variabel independen tersebut mempunyai pengaruh bermakna terhadap variabel dependen. Besarnya simpangan baku (S) adalah Rp77.202 sedangkan besarnya pengaruh variabel dependen secara simultan (R-Sq) adalah 78,6\% dan besarnya naik turun pengaruh variabel ( $\mathrm{R}-\mathrm{Sq}(\mathrm{adj})$ ) adalah 70,2\% sehingga 29,8\% variabel terikat dipengaruhi variabel-variabel lain.

\section{SARAN}

Pengelola objek wisata Pulau Tangkil dapat mengadakan event (acara) seperti acara musik atau hiburan pada waktu musim libur akhir tahun untuk menarik minat wisatawan untuk dapat berkunjung.

\section{DAFTAR PUSTAKA}

Arikunto, S. 2003.Prosedur Penelitian Suatu Pendekatan Praktek. Buku. Rineka Cipta. Jakarta.

Ekwarso. 2010. Nilai ekonomi lingkungan dan faktor-faktor yang mempengaruhi permintaan objek wisata air panas Pawan di Kabupaten Rokan Hulu (pendekatan biaya perjalanan). Jurnal Ekonomi. 18(3): 103-200.

Fauzi, R. 2013.Valuasi ekonomi Taman Nasional Kelimutu melalui pendekatan nilai ekonomi wisata. Tesis. Program Pascasarjanallmu Ekonomi, Universitas Indonesia. Jakarta.

Jayapalan, N. 2001. An Introduction to Tourism. Atlantic Publishers and Distributor. B, Vishal Enelave. New Delhi.

Mateka, A.J., I. Erlinda, N. Harahap. 2013. Obyek wisata pantai Balekambang Kabupaten Malang Jawa Timur. APi Student Journal. I (1): 12-22.

Pengelola Pulau Tangkil. 2015. Profil Pulau Tangkil. Tidak dipublikasikan.

Purwanto. 2013. Valuasi ekonomi ekowisata dengan model travel cost dan dampaknya terhadap usaha kecil pariwisata. Jurnal Manajemen dan Kewirausahaan.15(1):89102.

Safitri, M.,Hi.A. Siregar, dan B.D. Nasendi. 1996. Analisis wisata ekologi dan wisata budaya dengan metode kontingensidan biaya perjalanan. JurnalMajalah Duta Rimba. No. 197-198/XX/1996:5-6.

Shanty. 2011. Analisis persepsi wisatawan yang berkunjung ke Pulau Samosir. Tesis. Sekolah Pascasarjana. Universitas Sumatera Utara. Medan.

Sihotang, J.J., C. Wulandari., S. Herwanti. 2014. Nilai objek wisata air terjun Way Lalaan Provinsi Lampung dengan metode biaya perjalanan (Travel Cost Method). Jurnal Sylva Lestari. 2(3):11-18. 
Sobari, M. P.,A. Fauzi, Dan M. Iqbal. 2006. Analisis Nilai Ekonomi Taman Wisata Alam Laut Pulau Weh di Kota Sabang. Jurnal Mangrove dan Pesisir. 6(3): 44-59.

Tambunan, E. 2013.Analisisnilai ekonomiobyek wisata alam di Kabupaten Samosir Provinsi Sumatera Utara (studi kasus pemandianair panas di kelurahan Siogung-ogung, Kecamatan Pangururan).Skripsi.Fakultas Pertanian, Universitas Sumatera Utara.Medan.

Umar, H. 2007.Riset Pemasaran dan Perilaku Konsumen.Buku. PT.Gramedia. Jakarta.

Wawo, Mintje., A. James., H.S. Johana . 2008. Valuasi ekonomi wisata Pantai Hunimua Desa Liang Kecamatan Salahutu-Maluku Tengah.Jurnal Ichtyos. 8(1) : 49—54. 
Vol. 3 No. 3, September 2015 (71-84)

Halaman ini sengaja dikosongkan 